\section{Partial Gastrectomy For Peptic Ulcer: A Review Of 181 Cases Among British Military Personnel}

\section{Commentary}

\author{
ML Davies
}

This paper from 1957 reviewed the surgical treatment of peptic ulcer disease; a prevalent condition amongst the servicemen of the time and one which resulted in great cost, both to the soldier whose career was ruined and the army who had spent significant time and money in training them.

It reviewed the partial gastrectomies performed for peptic ulcer disease (PUD) in military hospitals from Japan to Northern Ireland over a five-year period and the figures reflect the work of 33 separate surgeons. There were difficulties in assembling the data, including poor co-operation from some hospitals, lost notes and lost patients - how little has changed! A total of 227 cases were notified, of which 181 were available for complete analysis. The author also submitted a follow-up questionnaire to the patient to grade their perceived clinical outcome, and to their GP who added their 'independent' opinion.

The results compared favourably with other studies of the time. Over $90 \%$ of patients had an improved, or excellent, grading following surgery, $7.4 \%$ were unchanged and only $1.5 \%$ were made worse by surgery. There were 5 deaths giving a mortality rate of $2.7 \%$. PULHEEMS grading was used as a marker of functional outcome, independent of the patients' perception and $158(87.3 \%)$ remained in a serving category of which $109(60.2 \%)$ were P2.

The author concluded that partial gastrectomy for PUD was an economically viable proposition in the army due to the high rate of good clinical outcome and the return to full fitness of the majority and to a restricted category for many more, although he recommends without clear justification that the operation be reserved for the regular soldier and only performed on national servicemen in cases of emergency. $\mathrm{He}$ suggests the reporting of all such cases in the future to a central register and for the continued long term follow up of the cases he reported. Furthermore, he concludes that, it is in the interests of the patient, as well as the service, that such a major operation be conducted by a small number of experienced surgeons, rather than by the 'occasional gastrectomist'. Colonel Hunt was clearly ahead of his time by advocating both ongoing audit of surgical results and surgical subspecialisation.

\section{Times Have Changed}

Developments in the treatment of PUD have come a long way since Hunt's day. The development of the H2-receptor antagonists in 1976 (1) saw the rapid decline of surgery for the treatment of PUD and the introduction proton pump inhibitors (PPI) has led to the virtual extinction of elective peptic ulcer surgery (2).

Peptic ulcer disease remains common with up to $40 \%$ of the population experiencing dyspeptic symptoms each year although only $2 \%$ seek help from their GP $(3,4)$ and the majority remain entirely within the primary care sector (4). The hospital clinician's role is now limited to managing patients with persistent or non-responsive disease, the exclusion of malignancy by upper gastrointestinal (UGI) endoscopy and the acute presentations of PUD as UGI bleeding or perforation.

The incidence of UGI bleeding (UGIB) is approximately 100 cases per 100,000 population per annum, with the highest incidence occurring in areas of the lowest socioeconomic status. It has an $11 \%$ mortality rate; this triples if the UGIB occurs in a patient already in hospital.

The management of acute UGIB is generally undertaken by medical gastroenterologists, although close collaboration with other specialities, especially surgery, is necessary. A typical management algorithm for UGIB is shown in Figure 1. Confirmation of the cause of UGIB is made at endoscopy during which therapeutic manoeuvres (injection sclerotherapy, endoclipping or argon beam coagulation) may be undertaken. Thereafter aggressive medical therapy with either oral or intravenous high dose PPI is appropriate $(5,6)$. Helicobacter Pylori eradication should be considered (3).

Re-bleeding or haemorrhage uncontrolled at endoscopy are indications for urgent surgical intervention and the decision to operate should be made by a senior surgeon capable of undertaking gastrectomy if necessary. Surgery in the early hours of the morning should be avoided if at all possible (3). There has only been a single trial comparing different surgical approaches in 


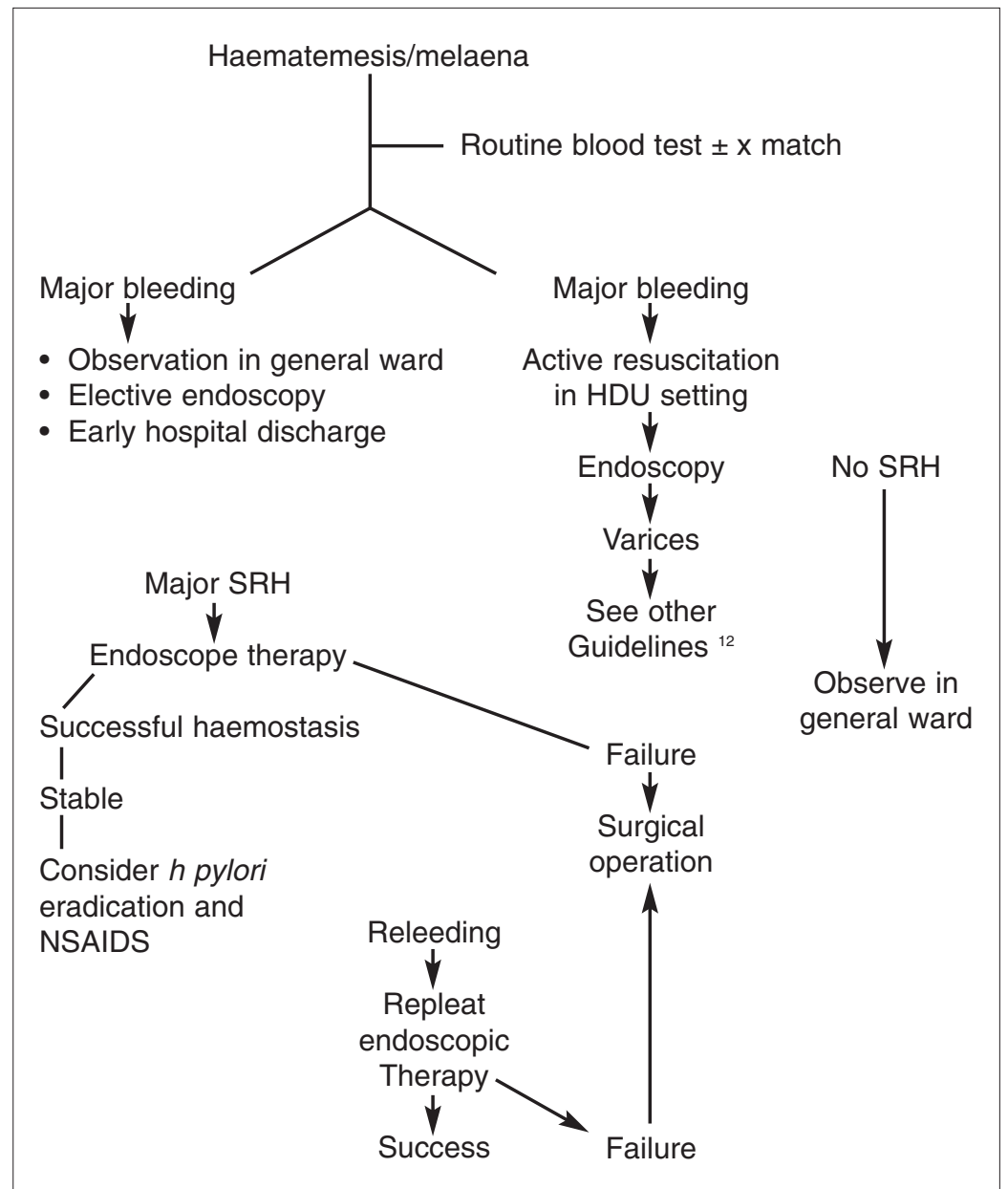

(HDU=high dependency unit; NSAIDs = non-steroidal anti-inflammatory drugs; $\mathrm{SRH}=$ stigmata of recent haemorrhage).

Fig 1. Algorithm for the management of acute gastrointestinal haemorrhage (3).

peptic ulcer disease (7). In bleeding duodenal ulceration re-bleeding rates were lower with gastrectomy (Bilroth I or II) compared to more conservative strategies but the bile leak rate was higher. There was no difference in overall mortality. Bleeding gastric ulcers are best treated by excision or partial gastrectomy.

When Hunt's paper is reviewed today it highlights several important points. Firstly, the enormous shift in treatment of PUD from surgical to medical, and the impact on surgical practice. Few modern surgical centres would be able to amass a series of nearly 200 gastrectomies for all indications over five years, let alone benign disease. Secondly, despite the recent advances in medical and endoscopic therapy for the complications of peptic ulcer disease the treatment algorithm still includes the requirement for a competent surgeon, able to undertake partial gastrectomy as an emergency when all other measure have failed. Finally, if as Hunt describes, this is not an operation for the 'occasional gastrectomist' there are huge implications for modern service provision and training. Should we continue to teach all surgical trainees to undertake gastric resections or should we reorganise our emergency surgical services to provide specialist upper gastrointestinal surgery on a regional or subregional basis?

\section{References}

1 Molinder HK. The development of cimetidine: 1964-1976. A human story. $\mathcal{F}$ Clin Gastroenterol 1994; 19(3): 248-54.

2 Modlin I, Kidd M. GERD 2003 issues from the past and a consensus for the future. Drugs of Today 2004; 40 (Suppl) A: 3-8.

3 British Society of Gastroenterology Endoscopy Committee. Non-variceal upper gastrointestinal haemorrhage: guidelines. Gut 2002; 51(Supp1 IV): iv1-iv6.

4 North of England Dyspepsia Guideline Development Group. Dyspepsia: Managing dyspepsia in adults in primary care. Newcastle Upon Tyne: University of Newcastle Upon Tyne 2004.

5 Hasselgren $\mathrm{G}$, Lind $\mathrm{T}$, Lundell $\mathrm{L}$ et al. Continuous intravenous infusion of omeprazole in elderly patients with peptic ulcer bleeding. Results of a placebo-controlled multicenter study. Scand FGastroenterol 1997; 32(4): 328-333.

6 Lin HJ, Lo WC, Lee FY, Perng CL, Tseng GY A prospective randomized comparative trial showing that omeprazole prevents rebleeding in patients with bleeding peptic ulcer after successful endoscopic therapy. Arch Int Med 1998; 158(1): 54-58.

7 Millat B, Hay JM, Valleur P, Fingerhut A, Fagniez PL. Emergency surgical treatment for bleeding duodenal ulcer: oversewing plus vagotomy versus gastric resection, a controlled randomized trial. World f Surg 1993; 17(5):568-573.

\section{RAMC Journal 1957 Vol 103 No. 2 198-203 Partial Gastrectomy For Peptic Ulcer A Review of 181 cases amongst British Military Personnel By Lt Col RS Hunt MBE FRCS(Ed)}

\section{Introduction}

During the five years 1950 to 1954 no fewer than 2,222 serving personnel were invalided from the army with a diagnosis of peptic ulcer. This figure includes all medical and surgical cases.

Not long ago a soldier who developed a chronic peptic ulcer was invalided and his army career thus came to an end. This was a serious matter both for him and the army. The army today, however, requires a soldier to be a highly skilled individual, often with a long and expensive technical training behind him, and it becomes all the more urgent to keep him fit and retain his services.

This review has been carried out in an effort to discover whether the results of 
partial gastrectomy in the army justify the retention of the soldier as a practical and economic proposition as regards both the time taken and the standard of health regained. It is also important to show that the standard of surgical skill in the army is high and compares favourably with that found in civil life.

While this individual review reveals the absence of a fully organised follow-up system in Army Records, there is sufficient material from which definite conclusions can be drawn. Owing to necessary postings no individual remains in the same station for sufficient time to allow a long-term follow-up of the results of such a major branch of surgery. It would seem right, therefore, to suggest that the material gathered for this review should be kept and added to and reviewed again after a period of time by some interested successor.

\section{Method}

This review covers a five-year period from the beginning of 1950 to the end of 1954. All military hospitals were asked to submit a nominal roll of patients who had undergone a partial gastrectomy for peptic ulcer during this period together with a résumé of their case histories. While this information was being gathered, the "present location" or "the last known address" of each patient was found by reference to the Unit Record Offices so that a follow-up questionnaire might be sent to the patients concerned.

Several difficulties at once became clear. Some hospitals which were known to have had such cases nevertheless submitted a "nil" return. In some instances case notes could not be obtained. Some Record Offices were unable to give the "present location" for security reasons, but were wiling to forward any communication. Thus direct contact was lost, with all the added waste of time and loss of personal interest. "The last known address" sometimes proved unreliable, for, having left the army, a patient often changed his address upon getting a new post.

It must therefore be admitted that the exact number of operations is not accurately known. Nevertheless a total of 227 cases were notified. Of these, 46 cannot be included, being incomplete for one or other of the reasons given above. Thus 20 per cent of the material known to exist is wasted from a research point of view, leaving 181 cases for study.

The follow-up questionnaire. The questions were so worded and arranged that the patient gave his own assessment of the clinical result. In addition, a space was left in which the patient's own doctor recorded his independent opinion, placing the patient into one of the four grades described below. Thus a very fair general assessment is made without the bias of any individual or panel. The four grades were:

1. Excellent

2. Improved

3. No change

4. Worse

To be "Excellent" the patient had to be completely symptom-free without any restrictions in diet and working capacity. To be "improved" he had to be able to do a full day's work, but suffered from minor symptoms readily amenable to simple treatment. Those in the "No change" group still had symptoms similar to those before operation or post-gastrectomy symptoms bad enough to keep their working capacity unchanged. Those in the "Worse" group had symptoms so severe that their working capacity was definitely reduced and they remained under treatment.

\section{Results}

Ogilvie (1953) states: "What should we ask of gastrectomy for the simple ulcer? The mortality should be negligible, well under 1 per cent, with a cure rate of at least 90 per cent. The remainder are not symptom-free, but they find the symptoms they are left with a small price to pay."

Table 1

\begin{tabular}{|c|c|c|c|c|c|c|c|c|}
\hline Authority & $\begin{array}{c}\text { No. of } \\
\text { cases }\end{array}$ & Excellent & Improved & Good* & $\begin{array}{c}\text { No } \\
\text { change }\end{array}$ & Worse & Poort & Died \\
\hline Finney et al. & 34 & Not & Not & 88.2 & Not & Not & 11.8 & Not \\
\hline Pulvertaft (1952) & 632 & 59.0 & 23.0 & 82.0 & $\begin{array}{c}\text { Stated } \\
15.0\end{array}$ & $\begin{array}{l}\text { Stated } \\
3.0\end{array}$ & 18.0 & Not \\
\hline Rauch (1952) & 893 & 26.4 & 63.6 & 90.0 & $\begin{array}{l}\text { Not } \\
\text { stated }\end{array}$ & $\begin{array}{l}\text { Not } \\
\text { stated }\end{array}$ & 10 & 2.7 \\
\hline $\begin{array}{l}\text { McDonald et al. } \\
\text { (1953) }\end{array}$ & $\begin{array}{l}\text { Not } \\
\text { stated }\end{array}$ & $\begin{array}{l}\text { Not } \\
\text { stated }\end{array}$ & $\begin{array}{l}\text { Not } \\
\text { stated }\end{array}$ & 82.0 & 4.0 & 4.0 & 8.0 & $\begin{array}{l}\text { Not } \\
\text { stated }\end{array}$ \\
\hline Ogilvie (1952) & $\begin{array}{l}\text { Not } \\
\text { stated }\end{array}$ & 93 & 5.6 & 98.6 & $\begin{array}{l}\text { Not } \\
\text { stated }\end{array}$ & $\begin{array}{l}\text { Not } \\
\text { stated }\end{array}$ & 1.4 & 2.7 \\
\hline Tanner (1954) & 91 & 59.6 & 32.2 & 91.8 & 3.3 & 4.9 & 8.2 & 1.0 \\
\hline $\begin{array}{l}\text { Goligher et al. } \\
\text { (1956) }\end{array}$ & 312 & 48.5 & 37.0 & 85.5 & 7.0 & 3.4 & 10.4 & 4.1 \\
\hline $\begin{array}{l}\text { British Army } \\
\text { (Present Series) } \\
(1954)\end{array}$ & 181 & 64.2 & 26.9 & 91.1 & 7.4 & 1.5 & 8.9 & 2.7 \\
\hline
\end{tabular}


To gauge the success or failure of the work done in the army, it is necessary to compare the results with this statement and with similar series done by other institutions or individuals. This has not proved easy, for although there are abundant statistics available, the standards used to gauge the results vary greatly. Indeed, in some cases it has been necessary to deduce figures from published results and to present them in two different ways in order to make comparisons fair and clear. The most readily comparable figures are presented as percentages in Table 1.

It will be seen that the British Army figures compare very favourably with the best in civil life both in this country and in America.

Mortality. The mortality of 2.7 per cent was made up as follows:

Burst duodenal stump 2

Leaking anatomosis 1

Massive collapse of lungs $\quad 1$

Pulmonary embolus $\quad$ Total 1

Three of these deaths must be attributed to the operation. The case notes concerning the man who died of massive collapse of the lungs suggest that death may have been due to anaesthetic difficulties. Pulmonary embolus is, of course, incidental to many different operations.

The civilian figures in Table 1 are the results produced by teams or individuals working in units accustomed to doing large numbers of gastric operations. The British Army figures are all the more interesting in that they reflect the work of no fewer than 33 different surgeons working in places as far apart as Japan and Northern Ireland. In fairness it must be stated, however, that the majority of the series were operated on in The Queen Alexandra Military Hospital, Millbank.

Table 2

\begin{tabular}{|c|c|c|}
\hline Final grading & Number of cases & Percentage \\
\hline P2 & 109 & 60.2 \\
P3 & 22 & 12.2 \\
P6 & 5 & 2.7 \\
P7 & 22 & 12.2 \\
P8 & 18 & 10.0 \\
Died & 5 & 2.7 \\
\hline
\end{tabular}

Table 3

Results (per cent) - Civilian classification

\begin{tabular}{|l|c|c|c|c|c|c|}
\hline \multicolumn{7}{|c|}{ Results (per cent) - Civilian classification } \\
\hline & No.of cases & Excellent & Improved & No change & Worse & Died \\
\hline Officers & 56 & 73.0 & 14.4 & 3.6 & 1.8 & 7.2 \\
N.C.Os & 101 & 58.4 & 32.7 & 6.9 & 1.0 & 1.0 \\
Other ranks & 17 & 41.2 & 35.3 & 23.5 & 0 & 0 \\
Females & 7 & 85.7 & 0 & 14.3 & 0 & 0 \\
\hline
\end{tabular}

Table 4

\begin{tabular}{|l|c|c|c|c|c|c|c|}
\hline \multicolumn{7}{|c|}{ Results (per cent) } & - Pulheems classifications \\
\hline & No.of cases & P2 & P3 & P6 & P7 & P8 & Died \\
\hline Officers & 56 & 65.8 & 10.8 & 1.8 & 7.2 & 7.2 & 7.2 \\
N.C.Os & 101 & 58.4 & 12.9 & 3.0 & 15.8 & 8.9 & 1.0 \\
Other ranks & 17 & 47.0 & 17.7 & 0 & 11.8 & 23.5 & 0 \\
Females & 7 & 71.4 & 0 & 14.3 & 0 & 14.3 & 0 \\
\hline
\end{tabular}

As the British Army figures compare well with the best in civil practice, it is important to co-relate them with the final "Pulheems" classification of the patients. Lengthy pamphlets explain the details of this method of grading, so that only a brief description is included here.

This method of grading is used by all three services and indicates the degree of functional ability of the individual. "P" indicates the overall physical standard, "U" the degree of function of the upper limbs, "L" that of the lower limbs, "E" "E" the acuity of vision, and " $\mathrm{M}$ " and " $\mathrm{S}$ " the mental state. Each entity is graded from 2, indicating full, normal functional capacity to 8 , which indicates a degree of disability requiring invaliding.

A lowered degree of function in any entities will invariably reflect on the "P" standard. Certain minimum standards are laid down for the various arms of the Service.

The final "Pulheems" classifications of the 181 cases are set out in Table 2 .

One hundred and fifty-eight patients (87.3 per cent) remained in a serving category and 109 (60.2 per cent) were fit for front line service in any part of the world within a year.

It is of some interest to note how the different ranks responded to treatment. The results are recorded in Tables 3 and 4 , classified both according to the civilian and Pulheems methods.

It is unwise to draw definite conclusions from such a small series, but it would appear from both sets of figures that the officer group had the best prognosis, the other ranks the worst, while the N.C.Os. were intermediate.

Type of operation. The types of gastrectomy recorded for the patients under review were as follows:

Antecolic Polya 103

Retro-colic Polya 44

Unspecified

Billroth

Total 181

Many sets of figures have been produced in favour of the different methods of doing this operation. The fact that they show that one operation benefits some patients but not others also indicates that no one operation benefits them all. In other words, each has its place. Unfortunately there is not as yet any certain way of knowing which is most suitable for any particular patient. It would be unwise, therefore, to limit the army surgeon to any particular type of partial gastrectomy. The above figures show the Polya type to be the most popular. It is important that further reviews should check the subsequent Pulheems classification of the cases included in this survey. Only thus is it possible to confirm that a soldier or 
officer can properly be classified P2 (fit for full active service in any part of the world) after he has undergone an apparently successful partial gastrectomy for peptic ulcer. With this object in view a register of all the patients having this operation has been compiled.

Complications requiring further surgery. The complications recorded in the 181 cases under review were as follows:

Reactionary haemorrhage

(due to slipped ligature)

Internal hernia

Stomal ulcer

Incisional hernia

Burst duodenal stump

Bilious vomiting

\section{Conclusions}

The surgical results in the army compare well with those in civil practice. The survey does not cover a long enough period to determine whether an officer or soldier still in a serving category should ever be properly graded $\mathrm{P} 2$. The fact that well over three-quarters of the cases are still in a serving category and over half are fit for full active service duties in any part of the world at the end of a year suggests that partial gastrectomy for chronic peptic ulcer is an economic proposition in the army.

The operation should be reserved for the Regular soldier and only done on the National Service man in cases of emergency. At present the operation should only be done in the United Kingdom. The
Pulheems Joint Service Systems of Medical Classification, para 94 (b) (i), 1951, rules that following partial gastrectomy a patient will remain in P7 for one year. This is not a foreign service grading. If such an operation were done abroad the patient would have to be returned to the United Kingdom in any case. Furthermore it is in the interest of the patient as well as those of the Service that such a major operation should be done by a few really experienced surgeons rather than by many "occasional gastrectomists."

All cases who have undergone this operation should be reported to a central authority for follow-up purposes. Further follow-up studies may indicate that the present Pulheems ruling as regards patients who have had this operation requires revision.

I am grateful to Major-General J. Huston, Q.H.S., FRCS., Director of Surgery, for his advice and encouragement and to Captain G. Tate, R.A.M.C, and Mr. A. E. Pridham, for their help.

\section{References}

FINNEY, J. M. J., \& Hanrahan, E. M. (1930). Ann. Surg., 92, 620

GOLIGHER, J. C., Moir; P. J. \& Wrigley, J. H (1956). Lancet, 1, 220

MCDONALD, O. G., Gillespie, M. G. La Bree, R. H (1953). A.M.A. Arch. Surg., 67, 44

OGILVIE, H. (1952). Brit. med. F., 2, 299

OGILVIE, H. (1953). Lancet, 1, 555.

PULVERTAFT, C. N. (1952). Lancet, 1. 225.

RAUCH, R. F. (1952). Surgery (St.Louis), 38, 638.

TANNER, N.C. (1954). Post Grad, med. F., 30, 448.

PULHEEMS: A Joint Service System of Medical Classification (1951), W.O. Code No. 6470. 